\title{
Temperatural conductivity of diluted water solutions graphen and nanostructures of graphen nanoparticles
}

\author{
O.M. Fesenko1 , V.V. Korskanov ${ }^{1}(0000-0001-8204-5728)$, V.B. Dolgoshey² (0000-0002-0147-3534), \\ E.S. Kifuk ${ }^{1}$, P.P. Pogoreckiy ${ }^{1}$ \\ 1 - Institute of physics of NAS of Ukraine, av. Nauki 46, Kyiv, 03028, Ukraine \\ Tel.: +380445251220 \\ E-mail: korskanov_valera@i.ua,fesenko@iop.kiev.ua \\ 2 - National Technical University of Ukraine "Igor Sikorsky Kyiv Polytechnic Institute”, av. Peremogy, Bldg. 19, Kyiv, \\ 03056, Ukraine \\ Tel.: +380931234802 \\ E-mail:vdolgoshey@ukr.net
}

Article info: received 24.02.2020, revised 03.03.2020, accepted 23.03.2020

Fesenko, O.M., Korskanov, V.V., Dolgoshey, V.B., Kifuk, E.S., Pogoreckiy, P.P. (2020) Temperatural conductivity of diluted water solutions graphen and nanostructures of graphen nanoparticles 1(46), DOI: 10.26909/csl.1.2020.4

The purpose of this work was to study the specific thermal conductivity of aqueous graphene dispersions and the diluted aqueous solution of nanostructures based on graphene and Au nanoparticles, as well as to determine the temperature and concentration dependences of the specific thermal conductivity of these aqueous dispersions.

The objects of study were aqueous dispersions of graphene and nanostructures based on graphene and Au nanoparticles. Graphene has characteristic dimensions of the order of $150-200 \mathrm{~nm}$ in the plane. The Au nanoparticles also have an average size of about $50 \mathrm{~nm}$ and a star-like shape. In dry nanocomposites, graphene is oriented parallel to the substrate plane, and nanostars are evenly distributed on the sample surface.

The specific volumetric thermal conductivity values of aqueous graphene dispersions and aqueous solutions of graphene-based nanoparticles and $\mathrm{Au}$ nanoparticles were obtained in the temperature range from $30^{\circ} \mathrm{C}$ to $60{ }^{\circ} \mathrm{C}$. A slight increase in the specific thermal conductivity was found with increasing temperature. The absolute values $a / v$ of aqueous graphene dispersions are 1,6 times higher than in three-component systems. The concentration dependences of the thermal conductivity of the two systems studied are linear. It is determined that the values of the specific thermal conductivity of dry graphene nanofillers are 1,62 times higher than the thermal conductivity of a mixture of graphene and Au nanoparticles.

Key words: aqueous graphene dispersions, nanostructures, thermal conductivity.

\section{Температуропровідність розбавлених водних розчинів графену та наноструктур графен-наночастинки золота}

\author{
О.М. Фесенко ${ }^{1}$ В.В. Корсканов ${ }^{1}$, В.Б. Долгошейํ, С.С. Кифюк ${ }^{1}$, \\ П.П. Погорецький ${ }^{1}$ \\ 1 - Інститут фізики НАН Украӥни, Київ, Украӥна \\ 2 - Національний технічний університет Украӥни “Київський політехнічний інститут імені Ігоря Сікорського”, \\ Київ, Украӥна
}

У температурному інтервалі від $30^{\circ} \mathrm{C}$ до $60^{\circ} \mathrm{C}$ визначено питому об'ємну температуропровідність водних дисперсій графену та водних розчинів наноструктур на основі графену та наночастинок Аu. Виявлено, незначне збільшення питомої температуропровідності при підвищенні температури. Абсолютні величини $a / v$ водних дисперсій графену у 1,6 рази вищі, ніж у трьохкомпонентних системах. Шляхом лінійної екстраполяції розраховані величини питомої температуропровідності сухих нанофлейків графену та суміші графену і наночастинок Аu. 


\section{Вступ}

Основними теплофізичними параметрами, які характеризують процеси теплопереносу у речовинах $є$ теплопровідність, теплоємність та температуропровідність. Для наноматеріалів, в умовах дуже обмеженого власного внутрішнього об'єму ці властивості набувають особливого значення, оскільки вони відображають інтенсивність передачі тепла (теплопровідність), процеси накопичення тепла (теплоємність) та швидкість дифузії температурних полів (температуропровідність).

Температуропровідність є однією з фізичних величин, що характеризують процеси теплопереносу i відображає динаміку зміни температури у речовині. Високе значення температуропровідності приводить до виникнення внутрішніх напруг при нагріваннi, або охолодженні i, як результат, до формування крихкої структури, оскільки швидкість власних структурних перебудов (обернена до часу структурної релаксації) буде меншою ніж швидкість зміни температури. Низька температуропровідність, навпаки, - приводить до формування більш гомогенної та міцної структури, оскільки у цьому разі швидкість внутрішніх перебудов вища ніж швидкість зміни температури. Саме тому однією з пріоритетних задач матеріалознавства $\epsilon$ розробка та формування матеріалів з регульованою температуропровідністю. Це обумовило зростаючий останнім часом інтерес до розробки та запровадження прямих експериментальний методів вимірювання температуропровідності нанокомпозитів. Вимірювання температуропровідності нанооб'єктів вимагає залучення безконтактних (оптичних) методів визначення температури [1 - 11].

В умовах стаціонарного теплового потоку коефіцієнт теплопровідності $a$ (тут і далі у системі СI) чисельно можна розрахувати за формулою [6]

$$
a=\lambda \cdot v / C_{p}=\lambda /\left(C_{p} \cdot \rho\right), \mathrm{M}^{2} / \mathrm{c}
$$

де $\lambda$ - теплопровідність, Вт/(м К); $v$ - питомий об'єм, м³/кг; $C_{p}$ - питома теплоємність, Дж/(кг·К); $\rho$ - густина речовини, кг/ $\mathbf{M}^{3}$.

3 практичної точки зору важливою $є$ інформація не про коефіцієнт температуропровідності, оскільки він для багатокомпонентних систем для різних напрямків теплового потоку може різнитися (анізотропія температуропровідності), а величина питомої температуропровідності $a / v$, тобто приведеної до одиниці питомого об'єму, як усереднена по всім напрямках і яку можна розрахувати по відомим значеннями теплопровідності та питомої теплоємності за формулою

$$
a / v=\lambda / C_{p}
$$

Ця величина відображає швидкість зміни температури в цілому по об'єму матеріалу.

Нещодавно нами були отримані експериментальні дані по теплоємності та теплопровідності водних дисперсій графену та наноструктур на основі графену, та водних розчинів наноструктур на основі графену та наночастинок $\mathrm{Au}$ [12]. Було виявлено, що при підвищенні вмісту нанонаповнювача в процесі випаровування води зростає і теплопровідність і теплоємність цих нанокомпозитів. Але питання поведінки температуропровідності цих нанокомпозитів зі зміною складу та температури нанокомпозитів (НК) досі залишилося відкритим.

Саме тому метою даної роботи було вивчення питомої температуропровідності водних дисперсій графену та розбавленого водного розчину наноструктур на основі графену та наночастинок $\mathrm{Au}$, а також визначення температурних та концентраційних залежностей питомої температуропровідності.

\section{Матеріали та методи досліджень}

Об'єктами досліджень слугували водні дисперсії графену та наноструктури на основі графену та наночастинок Au. Графен має характеристичні розміри порядку 150 - 200 нм у площині. Наночастинки Аu мають середній розмір близько 50 нм та зіркоподібну форму. У сухих нанокомпозитах графен орієнтований паралельно площині підкладки, а наностари рівномірно розподілені на поверхні зразка.

Водні дисперсії графену отримували шляхом додавання 1 мг графенового порошку до 500 мл дистильованої води та подальшого ультразвукового диспергування протягом 5 хвилин. Отриманий таким чином розчин (співвідношення компонентів вода/нанонаповнювач $w=0,002$ мас. частини) поміщали у вимірювальну калориметричну циліндричну комірку діаметром 8 мм і висотою 30 мм. Для приготування метал-графенових наноструктур до 0,2 мас. \% водного розчину графену додавали 20 мкл розчину наночастинок $\mathrm{Au}$ і завантажували у вимірювальну комірку. Далі вимірювали тепловий потік через зразок при нагріванні у режимі постійного теплового потоку. Для адекватності подальшого порівняння результатів всі зразки досліджувались при ідентичних умовах - однаковому температурному інтервалі і тепловому потоці через зразки.

Дослідження теплоємності та теплопровідності у температурному інтервалі від $30^{\circ} \mathrm{C}$ до $60{ }^{\circ} \mathrm{C}$ проводили за допомогою калориметричного модуля, принцип роботи якого детально було описано в [13]. 


\section{Результати та їх обговорення}

На рис. 1 приведені температурні залежності теплоємності і теплопровідності, а також розраховані за формулою (2) значення питомої температуропровідності.
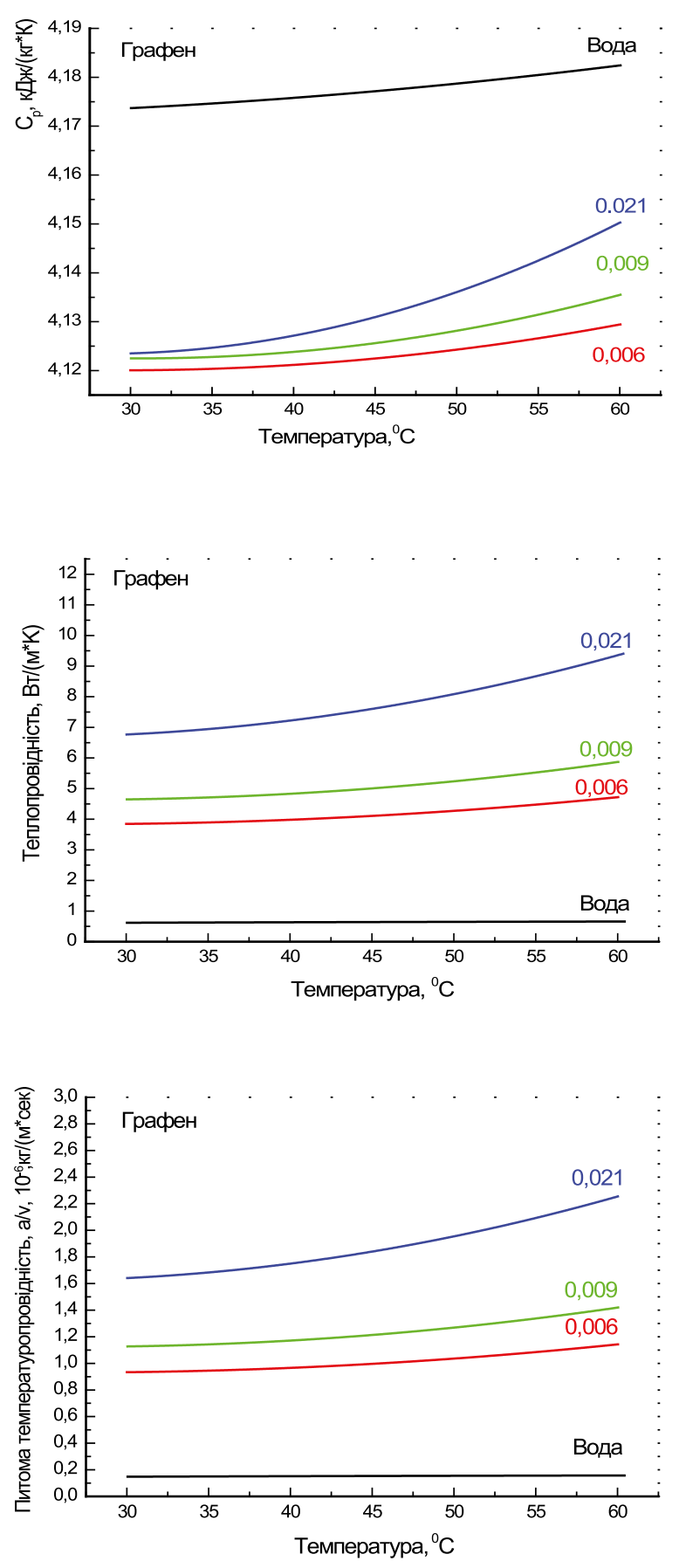

Аналізуючи представлені на рис. 1 результати слід зазначити, що абсолютні значення питомої теплоємності водних розчинів нанокомпозитів нижчі ніж питома теплоємність води (рис. 1а). На нашу думку, водним дисперсіям нанокомпозитів відразу після ультрадиспергування властива значна гете-
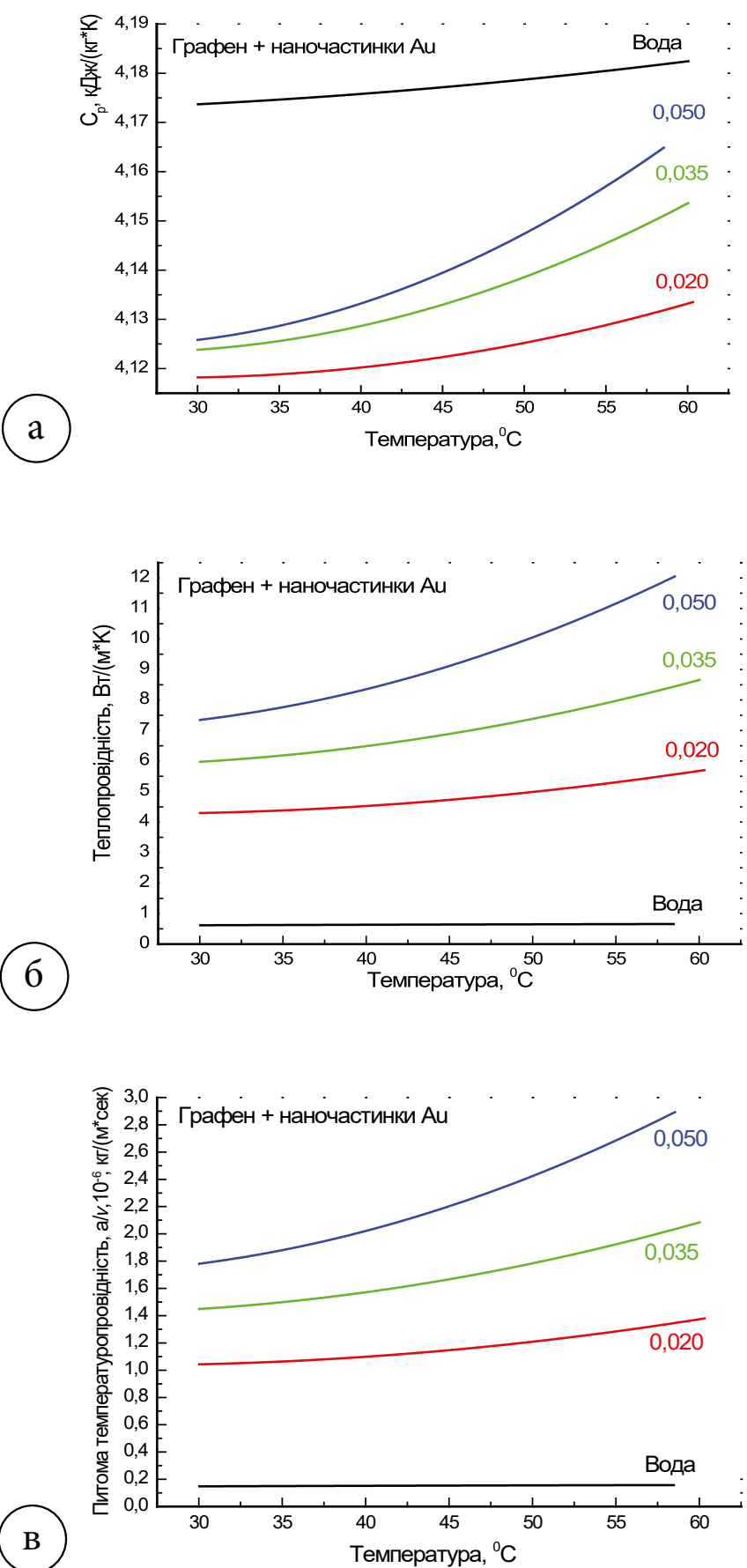

Рис. 1. Температурні залежності питомої теплоємності (а), теплопровідності

(б) та питомої температуропровідності (в) 
рогенність густини, яка обумовлює великі теплові втрати в результаті розсіювання теплових фононів на флуктуаціях густини та супутнє зниження питомої теплоємності. По мірі видалення води та збільшення концентрації нанонаповнювача відбувається його само агрегація. Оскільки зовнішня поверхня агрегатів із нанонаповнювача менша ніж сумарна поверхня диспергованих наночастинок того ж складу, то ці процеси супроводжуються зменшенням загальної гетерогенності зразків та падінням рівня розсіювання теплових фононів, що приводить до підвищення питомої теплоємності. Тобто збільшується частка акумульованого тепла по відношенню до розсіяного.

Теплопровідність водних розчинів, навпаки, вища ніж теплопровідність води (рис. 1б). Це пов'язано $з$ тим, що власна теплопровідність нанонаповнювачів набагато вища ніж у води [14, 15]. Тому зі збільшенням вмісту нанонаповнювача теплопровідність нанокомпозитів зростає. Аналогічно себе поводить і питома температуропровідність, яку було розраховано за формулою (2). Треба також відмітити, що при однаковому масовому вмісті нанонапованювача (при $w=0,02$ ) питома температуропровідність водних розчинів графену в середньому у 1,6 рази вища ніж питома температуропровідність наноструктур на основі графену і наночастинок Аu (рис. 1в). На нашу думку це пов'язано 3 кращою впорядкованістю водних розчинів графену у порівнянні з водними розчинами нанокомпозитів на основі графену і наночастинок $\mathrm{Au}$. Тобто за рахунок кращої впорядкованості вирівнювання температурних полів у водних дисперсіях графену відбувається швидше ніж у трьохкомпонентних системах.

На рис. 2 представлені концентраційні залежності питомої температуропровідності водних розчинів обох складів при різних температурах. Слід відзначити, що кути нахилу $d a / d w$ для водних розчинів графену вищі наноструктур на основі графену і наночастинок $\mathrm{Au}$. Це значить, що при додаванні графену до його водної диспеперсії відчутніше підвищує питому температуропровідність, ніж додавання тієї ж кількості графену і наночастинок Аu однакової кількості нанонаповнювачів до їх водного розчину. Причому кути нахилу $d a / d w 3$ температурою зростають (рис. 2б). Враховуючи лінійну концентраційну залежність питомої температуропровідності для обох типів водних розчинів була проведена екстраполяція $a / v$ до $w=1,0$ (тобто - до сухих нанокомпозитів). Виявилось, що питома температуропровідність сухих нанокомпозитів графену у середньому у 1,62 рази вища ніж температуропровідність наноструктур на основі графену і наночастинок $\mathrm{Au}$ (рис. 3).
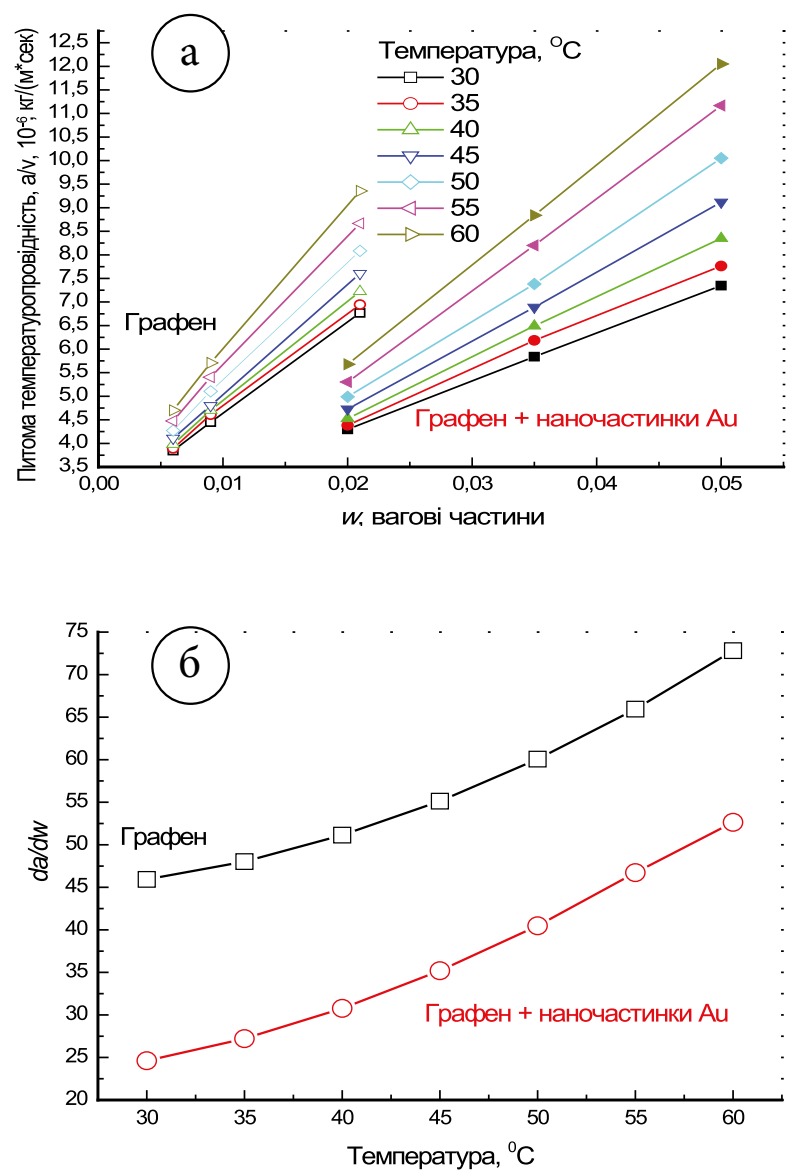

Рис. 2. Концентраційні залежності питомої температуропровідності водних розчинів графену та наноструктур на основі графену і наночастинок $\mathrm{Au}(\mathrm{a})$. Температурна залежність кута нахилу $d a / d w$ (б)

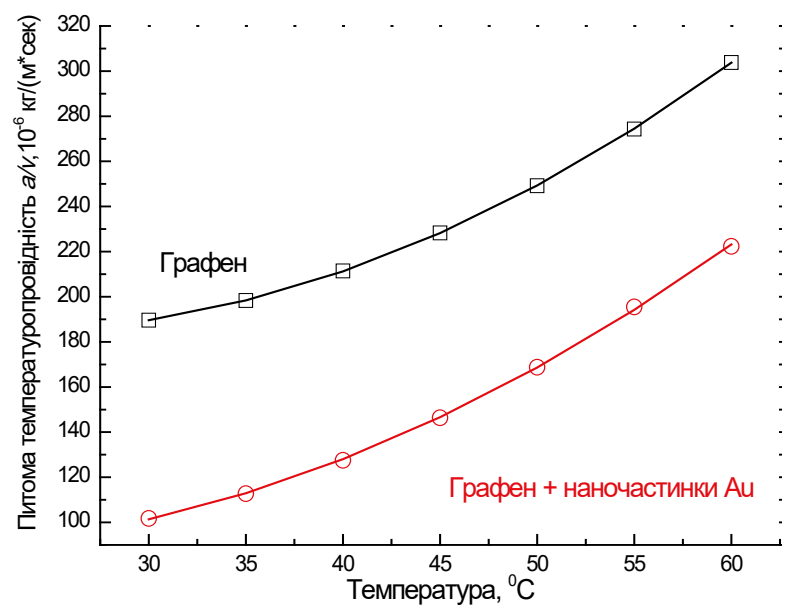

Рис. 3. Розраховані величини питомої температуропровідності сухих нанокомпозитів 


\section{Висновки}

Отримані величини питомої об'ємної температуропровідності водних дисперсій графену та водних розчинів наноструктур на основі графену та наночастинок Аu в температурному інтервалі від $30^{\circ} \mathrm{C}$ до $60{ }^{\circ} \mathrm{C}$. Виявлено незначне збільшення питомої температуропровідності при підвищенні температури. Абсолютні величини $a / v$ водних дисперсій графену у 1,6 рази вищі, ніж у трьохкомпонентних системах. Концентраційні залежності температуропровідності обох досліджених систем носять лінійний характер.

Визначено, що величини питомої температуропровідності сухих нанофлейків графену в 1,62 рази вищі ніж температуропровідність суміші графену і наночастинок Au.

\section{References}

1. Naseem, H, Murthy, H. (2019) A simple thermal diffusivity measurement technique for polymers and particulate composites. International Journal of Heat and Mass Transfer 137. - P. 968 - 978. https://doi. org/10.1016/j.ijheatmasstransfer.20.

2. Carr, EJ. (2019) Rear-surface integral method for calculating thermal diffusivity from laser flash experiments. Chemical Engineering Science 199. - P. 546 551. https://doi.org/10.1016/j.ces.2019.01.014.

3. Addepalli, S, Zhao, Y, Roy, R, Galhenege, $W$, Colle, $M$, Yu, J, Ucur, A. (2019) Non-destructive evaluation of localised heat damage occurring in carbon composites using thermography and thermal diffusivity measurement.Measurement 131. - P. 706 - 713. https://doi. org/10.1016/j.measurement.2018.09.040.

4. Soltaninejad, S, Husin, MS, Sadrolhosseini, AR, Zamiri, R, Zakaria, A, Moksin, MM, Gharibshahi, E. (2013) Thermal diffusivity measurement of Au nanofluids of very low concentration by using photoflash technique. Measurement 46 (10). - P. 4321 - 4327. https:// doi.org/10.1016/j.measurement.2013.07.043.

5. Dongmei, B, Huanxin, C, Shanjian, L, Limei, Sh. (2017) Measurement of thermal diffusivity/thermal contact resistance using laser photothermal method at cryogenic temperatures. Applied Thermal Engineering 111. - P. 768 - 775. https://doi.org/10.1016/j.applthermaleng.2016.07.188.

6. Kalyanavalli, V, Abilasha Ramadhas, TK, Sastikumar, D. (2019) Determination of Thermal Diffusivity of
Basalt Fiber Reinforced Epoxy Composite using Infrared Thermography.Measurement 134. - P. 673 - 678 . https://doi.org/10.1016/j.measurement.2018.11.004.

7. Genna, S, Ucciardello, N. (2019) A thermographic technique for in-plane thermal diffusivity measurement of electroplated coatings. Optics and Laser Technology 113. - P. 338 - 344. https://doi.org/10.1016/j.measurement.2018.11.004.

8. Giri, L., Tuli, S, Sharma, M, , Bugnon, Ph, Berger, H, \& Magrez, A. (2014). Thermal diffusivity measurements of templated nanocomposite using infrared thermography. Materials Letters 115. - P. 106 - 108. doi:10.1016/j.matlet.2013.10.042.

9. Li, Q., Takahashi, K., Zhang, X. (2019) Frequency-domain Raman method to measure thermal diffusivity of one-dimensional microfibers and nanowires. International Journal of Heat and Mass Transfer 134. P. 539 - 546. https://doi.org/10.1016/j.ijheatmasstransfer.2019.01.057.

10. Shahil, K.M., Balandin, A. (2012) Thermal properties of graphene and multilayer graphene: Application in thermal interfase materials // Solid State Communications 152. - P. 1331 - 1340. https://doi.org/10.1016/j. ssc.2012.04.034.

11. Chu, K., Wang, X., Li, Y. et al (2018) Thermal properties of graphene/metal composites with aligned graphene. Materials and Design 140. - P. 85 - 94. https://doi.org/10.1016/j.matdes.2017.11.048.

12. Фесенко, О.М., Корсканов, В.В., Цебрієнко, Т.В., Будник, О.П., Долгошей, В.Б. (2019) Вплив наночастинок золота на теплопровідність водних розчинів графену // Кераміка: наука і життя, 45(4). - С. 14 20. https://doi.org/10.26909/csl.4.2019.1.

13. Корсканов, В.В., Карпова, И.Л., Рухайло, М.В. ma ін. (2016) Калориметрический модуль для исследования теплофизических свойств композиционных материалов // Керамика: наука и жизнь 32 (3). C. 5 - 15.

14. Плотность золота, его теплоемкость и теплопроводность [Інтернет] [оновлено 2019 грудня 10; цитовано 2019 грудня 10]. Доступно: http://thermalinfo.ru/svojstva-materialov/metally-i-splavy/plotnost-zolota-ego-teploemkost-i-teploprovodnost.

15. Li, Q., Ma, W., Zhang, X. (2016) Laser flash Raman spectroscopy method for characterizing thermal diffusivity of supported 2D nanomaterials. International Journal of Heat and Mass Transfer. 95. P. $956-963$. 